\title{
Edge and corner effects in selective laser melting of IN 625 alloy
}

\author{
Gheorghe Matache*, Mihai Vladut, Alexandru Paraschiv, and Raluca Mihaela Condruz \\ Romanian Research, Development Institute for Gas Turbines, COMOTI, Bucharest, Romania
}

Received: 3 December 2019 / Accepted: 28 January 2020

\begin{abstract}
Experimental investigations on top surface of prismatic specimens, manufactured by Selective Laser Melting of IN 625 alloy, were carried out in order to assess the influence of laser power and scanning speed on edge and corner effects. Since the melt-pool behaviour is strongly influenced by the process parameters, all specimens were manufactured with no contour using the same layer thickness, hatch distance and scanning strategy at different levels of laser powers and scanning speeds. 3D laser surface scanning was performed in order to measure surface changes. The experimental results have revealed that melt-pool behaviour during solidification generates elevated ridges on both specimen sides and corners that are strongly influenced by the energy input. The edge ridges width increases with increasing the laser power and decrease with increasing the scanning speed, the rising of corners being much more pronounced. On the contrary, at constant laser power and variable scanning speeds the edge and corner ridges decrease.
\end{abstract}

Keywords: Edge effect / corner effect / selective laser melting / process parameters

\section{Introduction}

Among the additive manufacturing (AM) techniques of metal parts, selective laser melting (SLM) is a technique widely used for the production of components with high complexity. The utilization of SLM to manufacture components for high demanding industries is still limited and driven by the existing metal powder grades, efficiency and process cost. The SLM produced materials have a high level of anisotropy of structural and mechanical properties depending on the process parameters and build orientation [1-4].

Due to the high thermal gradients generated by the SLM process high levels of residual stress within the asbuilt part are encountered and usually post-treatment operations are required to avoid parts distortion [5]. Considering that more than 50 factors influence the melting [6,7] many negative effects can cause internal or surface defects in the manufactured parts such as: delamination and cracks, curling, warping, pores, undesired surface roughness or dimensional inaccuracy.

Various researches were made regarding the proper process parameters definition and it was observed that a number of process variables for AM are generally used to optimize different characteristics, targeting certain properties of the produced material. Typically, the dimensional accuracy, surface quality and other intrinsic properties of

\footnotetext{
* e-mail: gheorghe.matache@comoti.ro
}

SLM parts are related to variable process parameters such as: laser power, scanning speed, scanning strategy, layer thickness, hatch distance [8,9].

Several works were done in order to increase building rate by several times and to reduce costs by using higher layer thickness and coarser metal powders [10-12]. However, the increase of the layer thickness leads to the deterioration of the surface quality in the conditions in which anyway the roughness of SLM top surfaces is strongly different from the roughness of side surfaces [13].

The surface quality of components is mainly driven by the combination between laser power and deposition rates. Except the stair-stepping effect which appears as a result of layer-by-layer deposition that can be removed only by post processing operations, other defects were observed on part surface [14-16]. Roughness is one of the main surface defects observed on all AM parts and it is caused by the formation of balling phenomenon. Balling formation can be caused by the incongruous selection of process parameters (high speed and high power), the wettability of the powder or atmosphere oxygen content $[17,18]$. Studies were made regarding the process parameters influence on top and side surface roughness of IN 625 parts and was found that some combination of parameters can decrease the roughness on some surfaces while increasing it on the other surfaces $[19,20]$.

It was reported that this type of dimensional defects along with surface roughness can be caused by powders denudation as a result of high-pressure gas flow which affects the height of the melt track and extend the 
denudation phenomenon [21,22]. Moreover, rapid melting and solidification of metallic material generate high residual stresses that lead to defects such as microfractures and delamination between layers and formation of elevated edges or corners along with formation of key-hole porosities near the part's edge where heat can accumulate [23].

Only few studies about edge effects and dimensional accuracy were found. It was reported that defects including voids and porosities are prone to form near the edges than in the core. This is associated to the different core and contour scanning strategies where the speed and direction of the laser beam are changed [23]. Accordingly, when it is seeking to obtain high relative density parts then no contour scanning strategy is often preferred.

Other researchers proposed a hybrid process in order to remove the edge effect, consisting in a selective laser erosion applied after the part manufacturing by SLM [24].

The goal of the present work is to evaluate the influence of the laser power and scanning speed on edge and corner effect of SLM specimens manufactured with no contour.

\section{Material and methodology}

Vacuum gas atomized virgin IN 625 metal powder produced by LPW Technology Ltd. was used for the production of the specimens investigated within this work. The powder particle size ranges between 15 and $45 \mu \mathrm{m}$, having the particle size distribution $D_{10}=20 \pm 2 \mu \mathrm{m}$, $D_{50}=30 \pm 5 \mu \mathrm{m}$ and $D_{90}=45 \pm 5 \mu \mathrm{m}$. SEM examination of the raw material shows that the metal powder has a high degree of spheroidization, with smooth surface and a limited number of particles with some satellites.

The specimens were manufactured using a Lasertec 30SLM machine equipped with an ytterbium fibre laser with a maximum power of $600 \mathrm{~W}$. During manufacturing a constant oxygen level of $0.2 \%$ was kept in the machine building chamber by a constant supply of argon.

Specimens of $10 \times 10 \times 20 \mathrm{~mm}^{3}$ in size were built in vertical position on a stainless-steel building plate heated at $80^{\circ} \mathrm{C}$ using the same support material. Also, all specimens were manufactured with no contour in order to minimize the effect of other parameters and to eliminate the influence of contour on the edge and corner effect. For all specimens, the same layer thickness $(50 \mu \mathrm{m})$ and hatch distance $(0.1 \mathrm{~mm})$ were used along with a $67^{\circ}$ scanning strategy rotated with $90^{\circ}$ between two successive layers. The design of experiments consisted in manufacturing all specimens in the same job using six laser power levels (150, $200,250,300,350$ and $400 \mathrm{~W})$ and six scanning speeds $(0.5$, $0.6,0.7,0.8,0.9$ and $1.0 \mathrm{~m} \cdot \mathrm{s}^{-1}$ ) for each laser power level. Due to the very low energy input, the experiment for $150 \mathrm{~W}$ laser power and $1.0 \mathrm{~m} \cdot \mathrm{s}^{-1}$ was not performed.

The top as-built surfaces of the specimens (parallel to the $X-Y$ plane) were subject of $3 \mathrm{D}$ laser scanning investigation using a NIKON Altera 10.10 .8 coordinate measuring machine equipped with a non-contact NIKON LC15Dx laser scanning probe, with an accuracy of $1.9 \mu \mathrm{m}$. Figure 1 presents the specimens positioning on the building plate. The investigated surface is indicated by the blue block arrow.

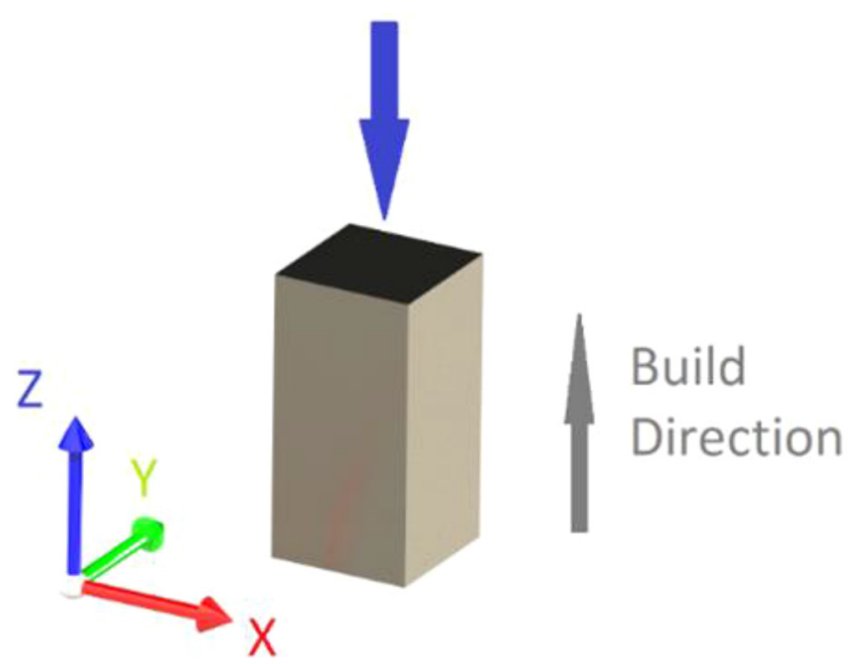

Fig. 1. Positioning of the specimens in the building position.

The surface topography of each sample was globally evaluated with an analysis allowance set to $5 \%$. Using the FOCUS 2019 machine software, data were post processed and numerically extracted and exported to excel for quantitative analysis of edge and corner effects.

\section{Results and discussion}

The experimental results have revealed that melt-pool behaviour during solidification generates elevated ridges on both specimen sides and corners. Figure 2 presents the macrograph of the top surface of the specimen built with $250 \mathrm{~W}$ laser power and $0.7 \mathrm{~m} \mathrm{~s}^{-1}$ scanning speed. The surface topography of the specimen shows the melting tracks, as well as the elevated ridges of sides and corners. The associated 3D scanned topography of the same specimen is shown in Figure $2 \mathrm{~b}$.

The investigation of top surfaces of the samples manufactured with two variables have shown that during manufacturing with no contour both laser power and scanning speed strongly influence the texture and the topography of the part surface. The experimental results have revealed that during solidification elevated ridges of different sizes are generated on both specimen sides and corners.

Other material characteristics influenced by the two process parameters such as porosity, relative density, defects occurrence are not subject of the current paper. Figure 3 presents the top surface topography of the specimens built with low $(150 \mathrm{~W})$ and high $(350 \mathrm{~W})$ laser powers using the same 0.5 and $0.9 \mathrm{~m} \cdot \mathrm{s}^{-1}$ scanning speed. The specimens surface topography clearly shows the influence of the process parameters on the width of the elevated side ridges.

In order to quantitatively assess the influence of the process parameters on side and corner effect, all samples were investigated in two directions as shown in Figure 4. Section $\mathrm{X}$-X parallel to the $X$-axis of the samples was used to assess the edge effect while the section D-D (diagonal of the samples section, parallel to the $X-Y$ plane of the 


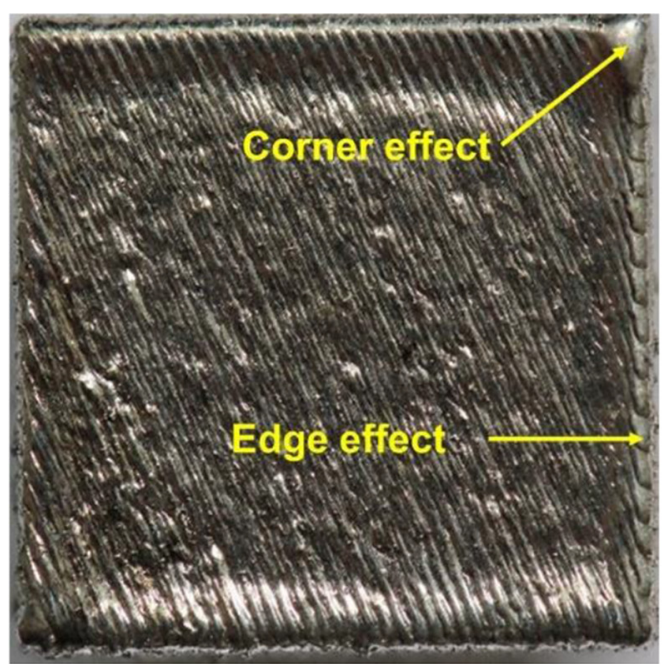

(a)

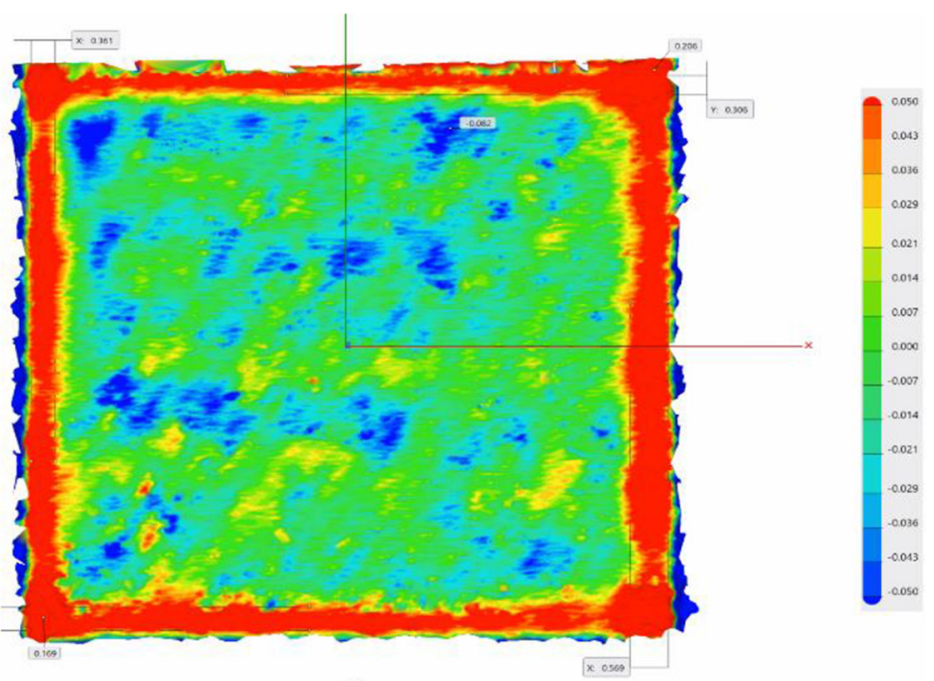

(b)

Fig. 2. Macroscopic view of the top surface and the associated scanned surface topography of the specimen built with $250 \mathrm{~W}$ laser power and $0.7 \mathrm{~m} \cdot \mathrm{s}^{-1}$ scanning speed. The real side of the specimen $-10 \mathrm{~mm}$.

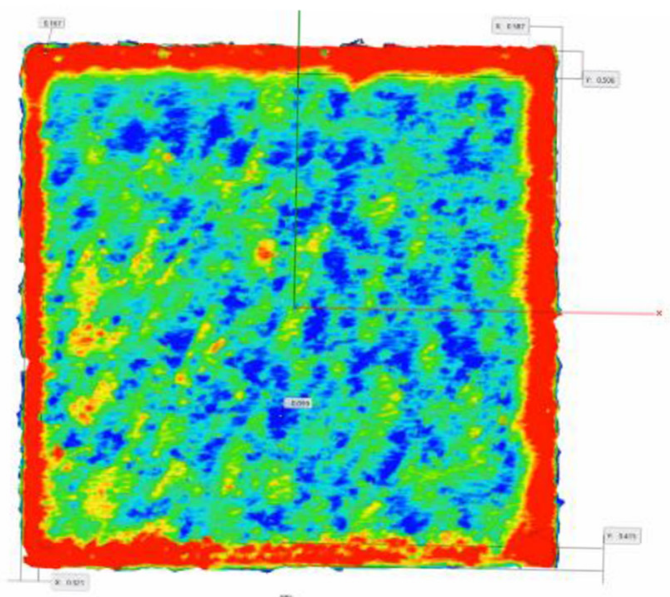

(a)

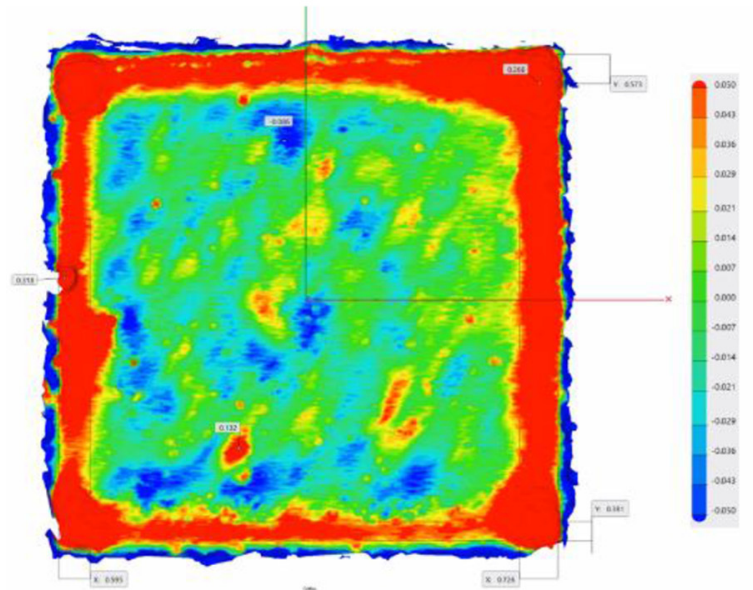

(c)

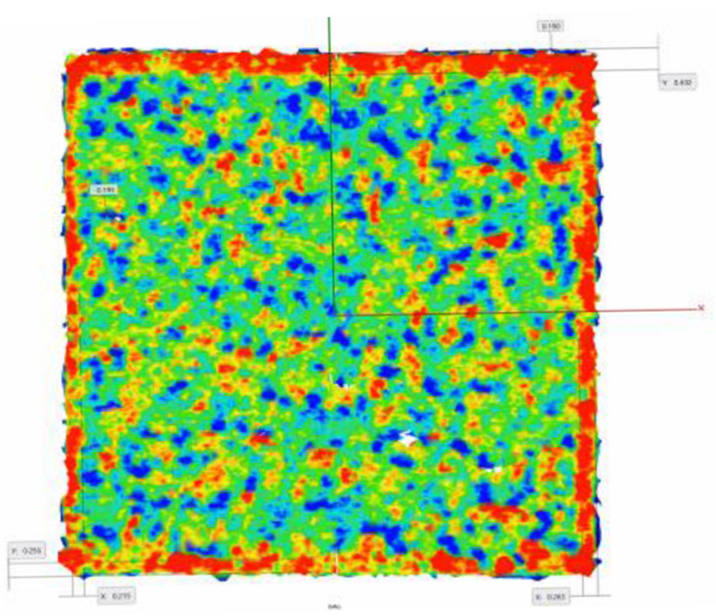

(b)

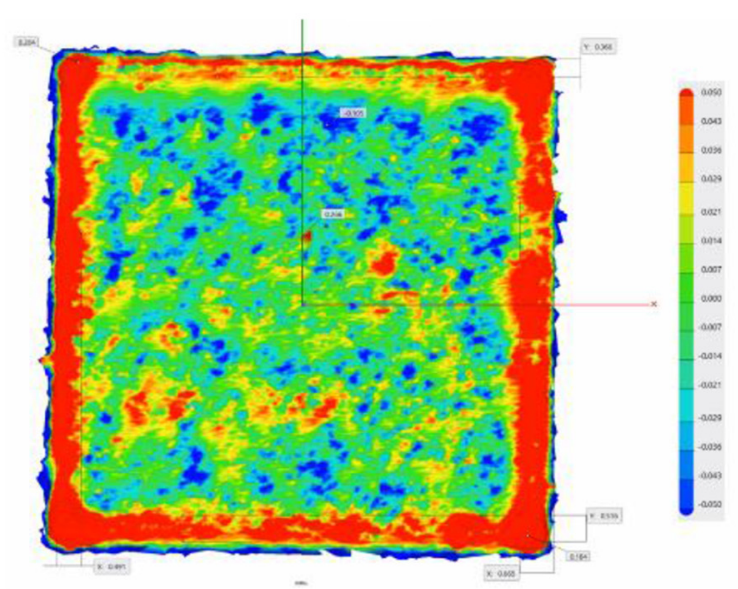

(d)

Fig. 3. Surface topography of the specimens built with constant $150 \mathrm{~W}$ laser power and $0.5 \mathrm{~m} \cdot \mathrm{s}-1(\mathrm{a})$ and $0.9 \mathrm{~m} \cdot \mathrm{s}^{-1}(\mathrm{~b})$, and with $350 \mathrm{~W}$ laser power and $0.5 \mathrm{~m} \cdot \mathrm{s}-1$ (c) and $0.9 \mathrm{~m} \cdot \mathrm{s}^{-1}(\mathrm{~d})$ scanning speeds. 


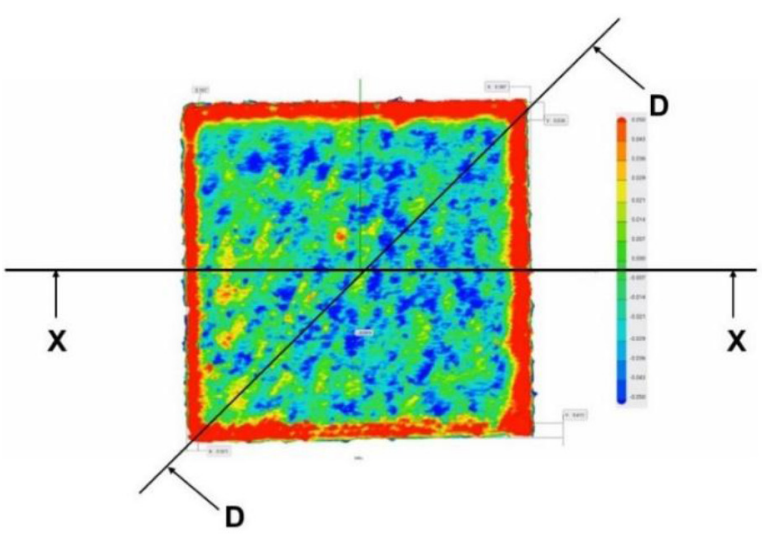

(a)

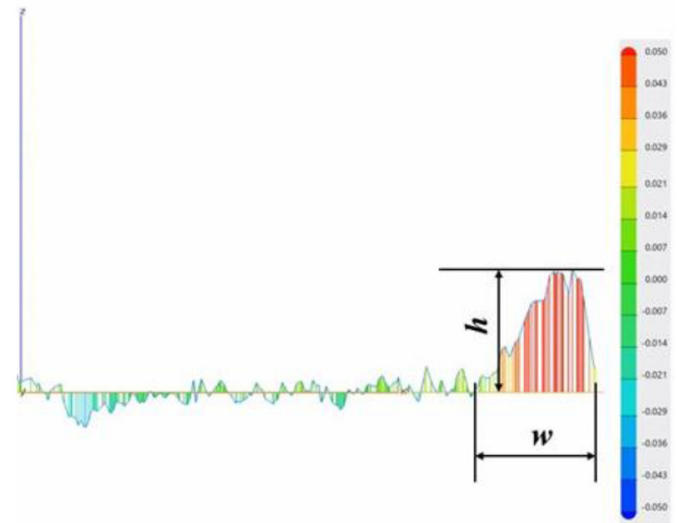

(b)

Fig. 4. Sections used for the assessment of edge and corner effect (a) by measurement of edge and corner height and width (b).

building plate) was used for the investigation of the corner effect. The quantitative analysis of the edge and corner effects was done by measurement of the edge and corner heights $(\mathrm{h})$ and edge width $(\mathrm{w})$ using the data extracted from the surface profiles of the 3D laser scans on the two sections as shown in Figure $4 \mathrm{~b}$ for $\mathrm{X}-\mathrm{X}$ section of the specimen built with $150 \mathrm{~W}$ laser power and $0.5 \mathrm{~m} \cdot \mathrm{s}^{-1}$ scanning speed.

The edge and corner heights $(\mathrm{h})$ were measured as the maximum height towards the average value of the flat surface, while the edge width (w) was measured as the distance between the specimen side and the point where the side elevated ridges end.

Optical micrographs of the as-built specimens taken in $\mathrm{X}-\mathrm{X}$ section presented in Figure 4a, manufactured with low $(150 \mathrm{~W})$ and high $(400 \mathrm{~W})$ laser power and the same scanning speed of $0.6 \mathrm{~m} \cdot \mathrm{s}^{-1}$, are presented in Figures 5 and 6 . The micrographs at low order of magnitude $(50 \times)$ show the edge effect occurrence in both cases, as well as typical features encountered in SLM materials. Both micrographs show the fusion lines, the melt pools shape and defects associated with low or high energy input.

At low energy input (low laser power and scanning speed), porosities are usually formed between successive layers by the incorporation of gas bubbles (keyhole porosities). Using high laser power there is enough energy input to partly remelt the previous layer and to avoid keyhole porosities formation. However, at low scanning speeds, the liquid pools are pulverized and spatters are randomly projected on the top surface of the built solid parts and on the powder bed sticking to the part as shown in Figure 6. Such sticked particles may occur either by liquid metal sputtering at high power and low speed or by sticking metal powder particles from the powder bed by the liquid pool, or both.

The analysis of measurements shows that process parameters, laser power and scanning speed, have strong influence on the edge ridge formation even at lower laser power. Figure 7 presents the variation of the edge width as a function of laser power and scanning speed. It can be noticed that at constant scanning speed, increasing the laser power caused an increase of the width of side ridges.

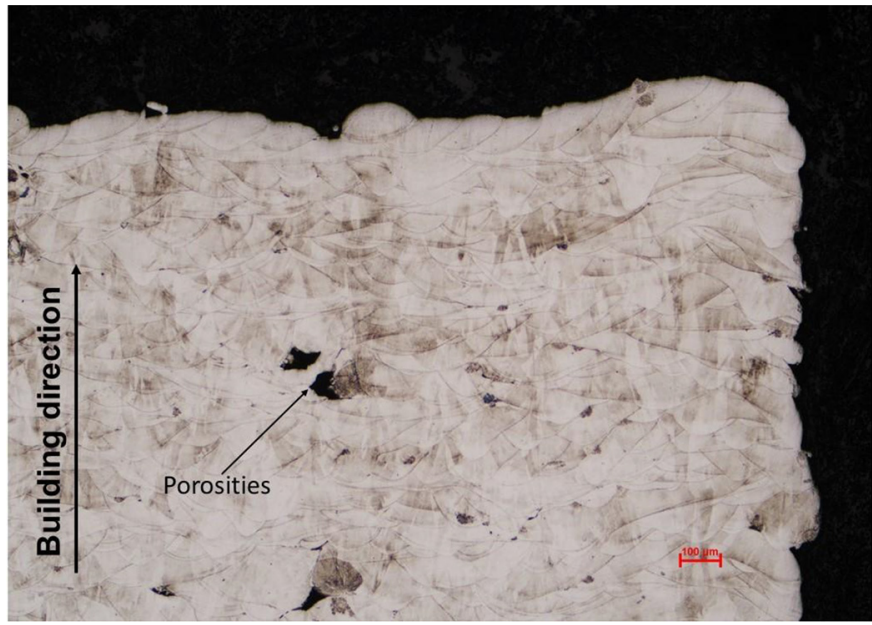

Fig. 5. Microstructure of the specimen manufactured with $150 \mathrm{~W}$ laser power and $0.6 \mathrm{~m} \cdot \mathrm{s}^{-1}$ scanning speed. Etchant aqua regia.

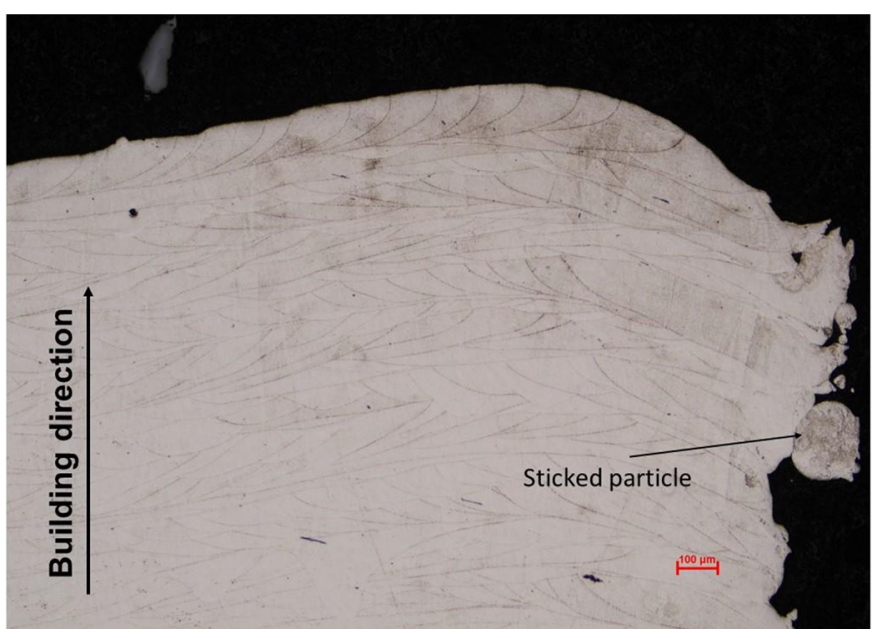

Fig. 6. Microstructure of the specimen manufactured with $400 \mathrm{~W}$ laser power and $0.6 \mathrm{~m} \cdot \mathrm{s}^{-1}$ scanning speed. Etchant aqua regia. 


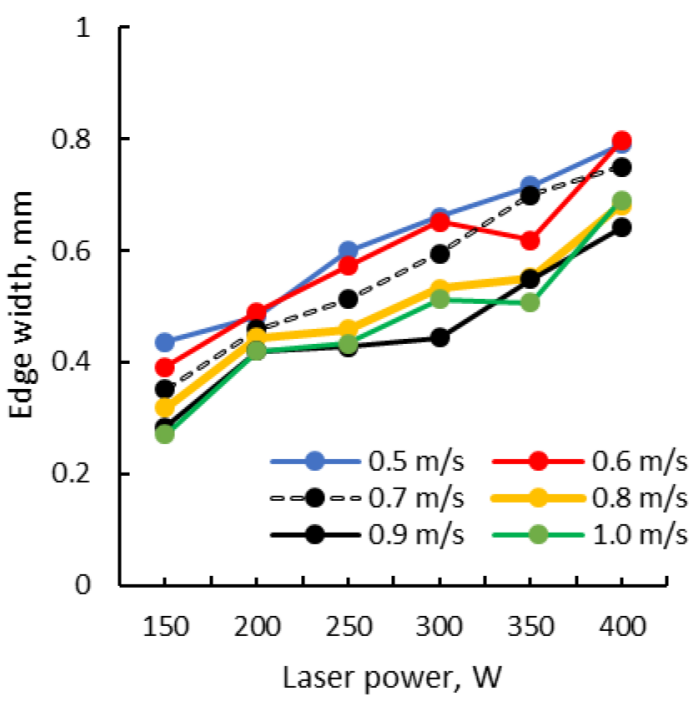

(a)

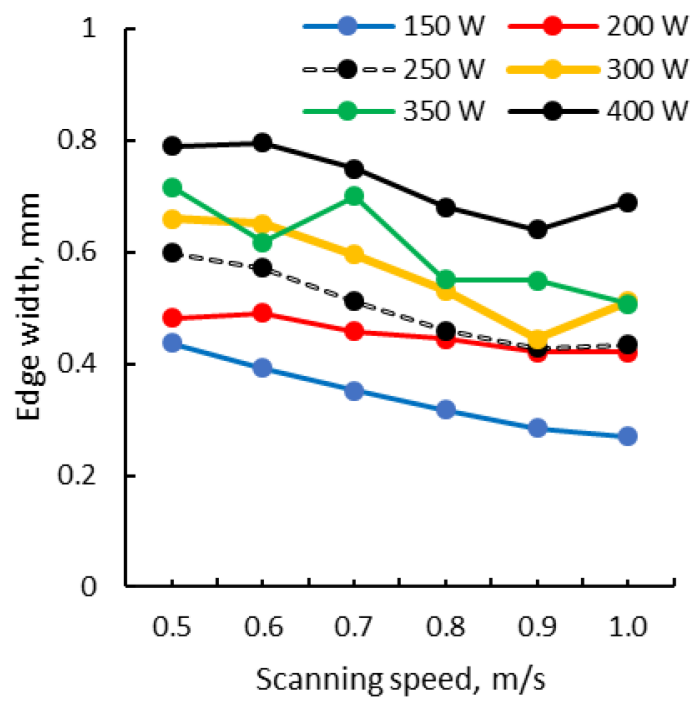

(b)

Fig. 7. Edge width as a function of laser power (a) and scanning speed (b).

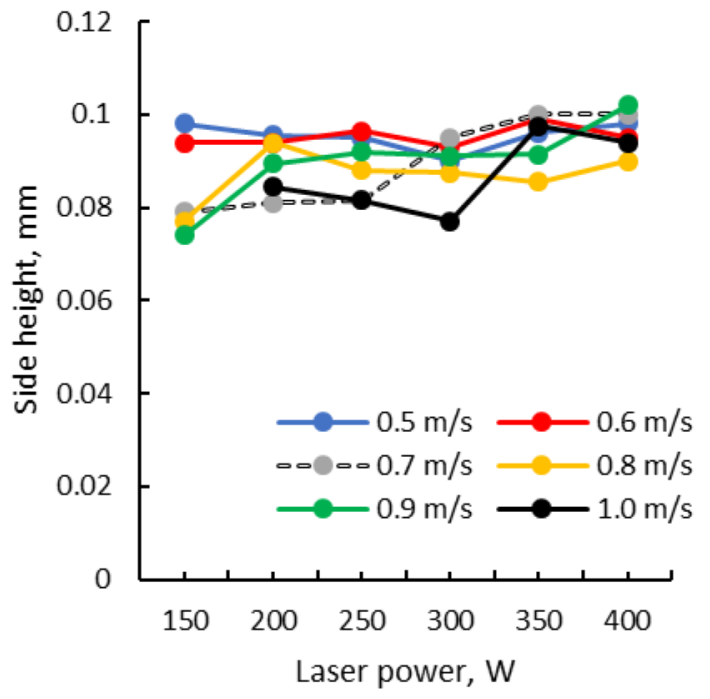

(a)

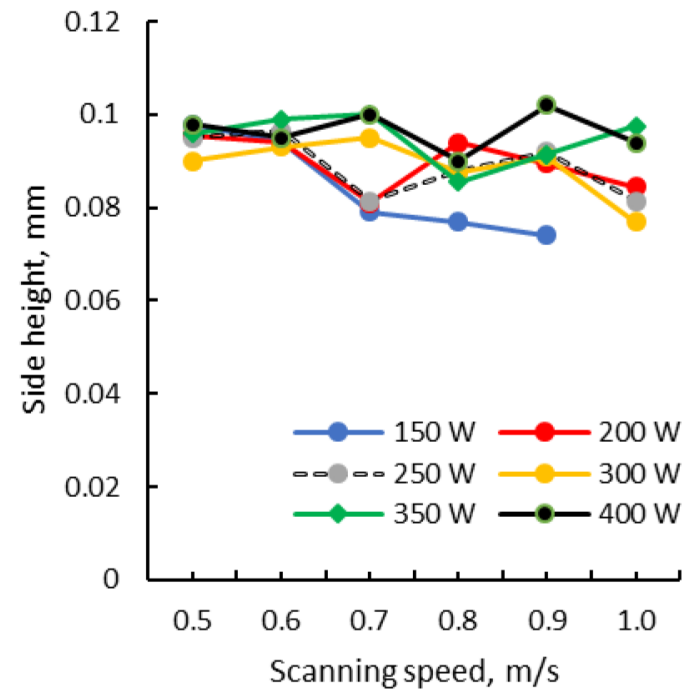

(b)

Fig. 8. Side ridge height as a function of laser power (a) and scanning speed (b).

For example, in the case of specimens built with constant scanning speed of $0.7 \mathrm{~m} \cdot \mathrm{s}^{-1}$ and various laser powers, the edge width increases from 0.35 to $0.72 \mathrm{~mm}$ (Fig. 7a).

This upward trend of side ridges observed in case of maintaining a constant speed and increasing the laser power was also found at other different speed levels. On the contrary, maintaining a constant laser power and modifying the laser speed lead to decrease of the side ridge width (Fig. 7b).

The measurements show that the side ridge heights are also influenced by the process parameters but in lesser extent. Although it has the same tendency to increase with laser power increase and to decrease with the increase of scanning speed, the side ridges height varies not so much accentuated as in the case of the edge width (Fig. 8). With the increase of the laser power from $150 \mathrm{~W}$ to $400 \mathrm{~W}$ the edges are more pronounced, in particular at low scanning speeds. Due to the high energy input at high laser power and low scanning speed, the molten pool becomes unstable and the high energy input generates a recoil pressure that pushes the melt. The melt pushed at the edge of the part solidify rapidly and generate the edge ridge. At high scanning speeds the turn of the laser scanning direction is faster and partly pushes back on laser track the metal that is still liquid. Thus, with the increase of scanning speed the edge height is diminished, in particular for low laser powers as shown in Figure 8b.

Unlike the edge ridge heights, the measurements of the specimen's corner heights show a strong influence of the process parameters on the surface texture as presented in Figure 9. The increase of the laser power from $150 \mathrm{~W}$ to $400 \mathrm{~W}$ generates the increase of the corner heights from 0.1 $0.15 \mathrm{~mm}$ to almost $0.3 \mathrm{~mm}$ for the lowest scanning speed (Fig. 9a). It can be noticed that for high input energies, 


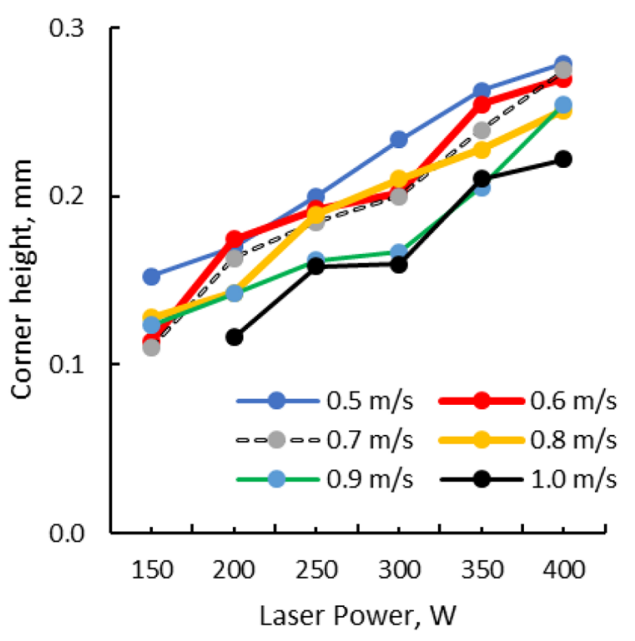

(a)

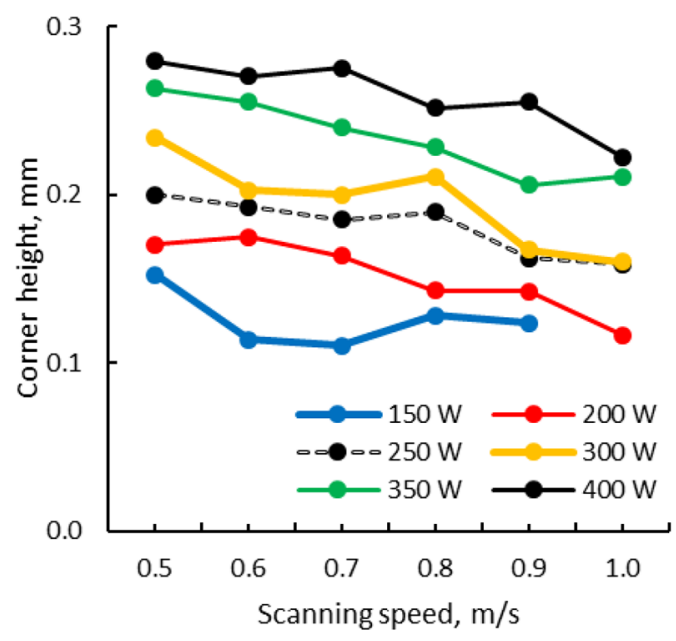

(b)

Fig. 9. Corner height as a function of laser power (a) and scanning speed (b).

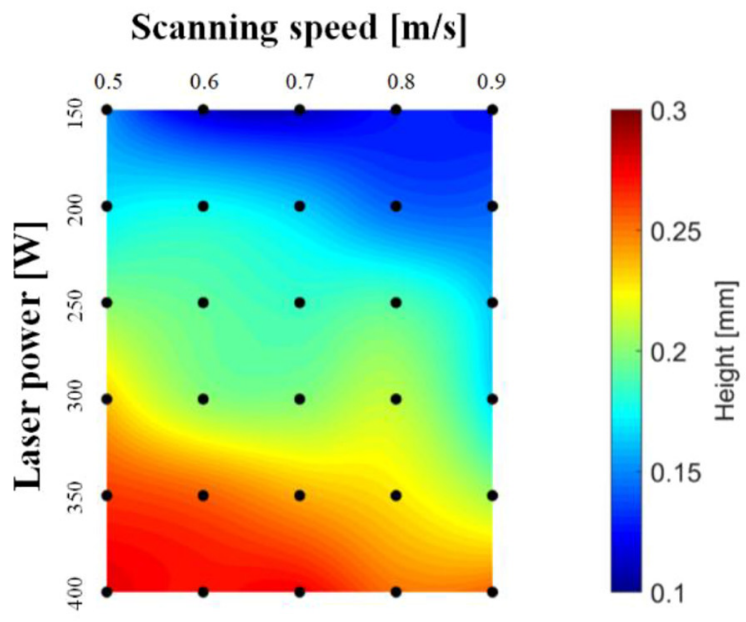

(a)

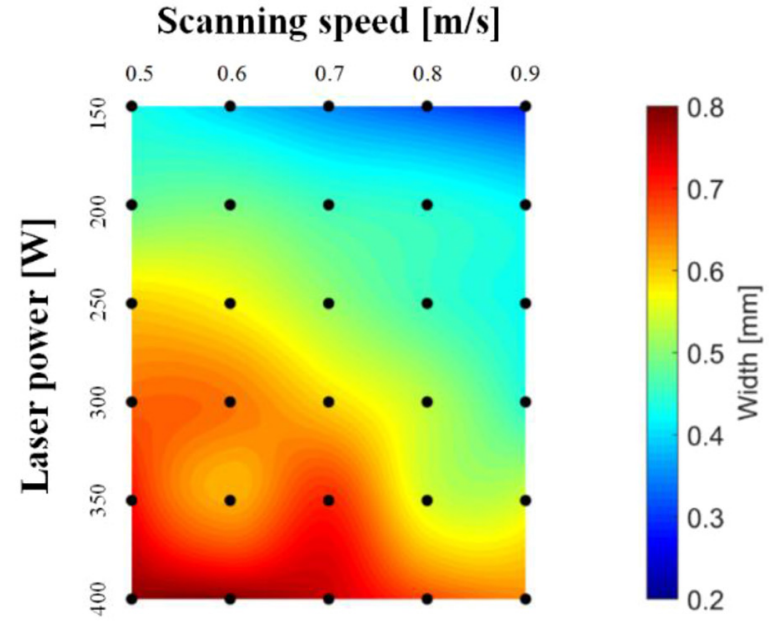

(b)

Fig. 10. (a) Corner height contour plot with laser power and scanning speed as process variables and (b) side width contour plot with laser power and scanning speed as process variables.

laser powers over $250-300 \mathrm{~W}$ and low scanning speeds (less than $0.6 \mathrm{~m} \cdot \mathrm{s}^{-1}$ ), the height of the corners even exceeds the thickness of the next layer of powder, and so they are simply remelted in the following sequence. As in the case of edge width, the corner height decreases with increasing the scanning speed (Fig. 9b).

The fitted 2D contour plots of corner height and side width presented in Figure 10 summarize the experimental data points with different combinations of laser power and scanning speed as process variables.

Based on the measurements presented it can be observed that maximum values of edges width and corners height are obtained in the case of using higher values of laser power and lower values of scanning speed. Using a high power and low speed (high energy input) a substantial vaporization of the material is produced due to excessive amounts of heat to material which creates a very unstable molten pool and a recoil pressure that pushes the melt in side. As the energy increases the surface deformation of the manufactured specimens will be produced due to increasing of edges and corners dimensions. The metal vaporization and the recoil pressure generated by the excessive amounts of heat allow a deep laser penetration and cause a development of a vapour cavity which can collapse and leave voids. This regime is known as keyhole mode regime [25].On the other hand, using a low power and high speed will produce small deformations but not provide enough power to fully melt the powder. Also, the surface tension will drive the melt pool, which is more elongated for high scanning speeds, to break up into smaller droplets (balling). So, by balancing appropriate values of the laser power between 250 and $300 \mathrm{~W}$ and scanning speeds between 0.7 and $0.8 \mathrm{~m} \cdot \mathrm{s}^{-1} \mathrm{a}$ more stable melt is obtained. 


\section{Conclusion}

The experimental results have revealed that melt-pool behaviour during solidification generates elevated ridges on both specimen sides and corners that are strongly influenced by the energy input done by laser power and scanning speed.

With the increase of laser power from 150 to $400 \mathrm{~W}$, at constant scanning speed, both edge and corner ridges increase, the rising of corners being much more pronounced. On the contrary, at constant laser power and variable scanning speeds between 0.5 and $1.0 \mathrm{~m} \cdot \mathrm{s}^{-1}$ the edge and corner ridges decrease, less obvious in the case of the edges.

It was also highlighted that the edge ridges width follows the same trend. The edge ridges width increases with increasing the laser power and decrease with increasing the scanning speed.

Within the experimental process parameters range, laser power between 250 and $300 \mathrm{~W}$ and scanning speeds between 0.7 and $0.8 \mathrm{~m} \cdot \mathrm{s}^{-1}$ generate a more stable melt, with elevated edges and corners less than the metal powder layer deposed at each recoating sequence.

Beside the already proposed erosion hybrid process, the top surface edge effect removal might consider additional remelting of the last layer, without powder addition, using lower energy inputs with laser power in the range of 150 and $200 \mathrm{~W}$ and high scanning speeds which experimentally showed to produce smaller deformations. Alternatively, the building strategy might consider the melting the last few powder layers with low energy input, i.e., low laser power and high scanning speed.

The activity is carried out under a programme of, and funded by, the European Space Agency. The view expressed in this publication can in no way be taken to reflect the official opinion of the European Space Agency.

\section{References}

1. L. Hitzler, J. Hirsch, B. Heine, M. Merkel, W. Hall, A. Öchsner, Materials 10 (2017) 1136

2. Y. Kok, X.P. Tan, P. Wang, M.L.S. Nai, N.H. Loh, E. Liu, S. B. Tor, Mater. Des. 139 (2018) 565-586

3. M. Ni, C. Chen, X. Wang, P. Wang, R. Li, X. Zhang, K. Zhou, Mater. Sci. Eng. A 701 (2017) 344-351

4. D. Denga, J. Moverare, R.L. Peng, H. Söderberg, Mater. Sci. Eng. A 693 (2017) 151-163
5. T. Mishurova, S. Cabeza, K. Artzt, J. Haubrich, M. Klaus, C. Genzel, G. Requena, G. Bruno, Materials 10 (2017) 348

6. M. Letenneur, A. Kreitcberg, V. Brailovski, J. Manuf. Mater. Process. 3 (2019) 1

7. M. Mani, S. Feng, B. Lane, A. Donmez, S. Moylan, R. Fesperman, Additive Manufacturing Handbook: Product Development for the Defense Industry, A.B. Badiru, V.V. Valencia, D. Liu (Eds.) CRC Press, Boca Raton, 2017, pp. 629-676

8. A.H. Maamoun, Y.F. Xue, M.A. Elbestawi, S.C. Veldhuis, Materials 11 (2018) 2343

9. A.M. Khorasania, I. Gibsond, U.S. Awana, A. Ghaderic, Add. Manuf. 25 (2019) 176-186

10. X. Shi, S. Ma, C. Liu, C. Chen, Q. Wu, X. Chen, J. Lu, Materials 9 (2016) 975

11. M. Ma, Z. Wang, M. Gao, X. Zeng, J. Mater. Process. Technol. 215 (2015) 142-150

12. S. Bremen, M. Wilhelm, D. Andrei, Laser Tech. J. 9 (2012) 33-38

13. M. Król, T. Tanski, Arch. Metall. Mater. 61 (2016) 12911296

14. T. DebRoy, H.L. Wei, J.S. Zuback, T. Mukherjee, J.W. Elmer, J.O. Milewski, A.M. Beese, A. Wilson-Heid, A. De, W. Zhang, Prog. Mater. Sci. 92 (2018) 112-224

15. S.F. Siddiqui, A.A. Fasoro, A.P. Gordon, Additive Manufacturing $\mathrm{H}$ and book: Product Development for the Defense Industry, A.B. Badiru, V.V. Valencia, D. Liu (Eds.), CRC Press, Boca Raton, 2017

16. N.N. Kumbhar, A.V. Mulay, J. Inst. Eng. India Ser. C (2016)

17. W.J. Sames, F.A. List, S. Pannala, R.R. Dehoff, S.S. Babu, Int. Mater. Rev. (2016)

18. R. Li, J. Liu, Y. Shi, L. Wang, W. Jiang, Int. J. Adv. Manuf. Technol. 59 (2012) 1025-1035

19. K. Mumtaz, N. Hopkinson, Rapid Prototyp. J. 15 (2009) 96103

20. J.C. Fox, S.P. Moylan, B.M. Lane, Proc. CIRP 45 (2016) 131-134

21. S.A. Khairallah, A.T. Anderson, A. Rubenchik, W.E. King, Acta Mater. 108 (2016) 36-45

22. M.J. Matthews, G. Guss, S.A. Khairallah, A.M. Rubenchik, P.J. Depond, W.E. King, Acta Mater. 114 (2016) 33-42

23. A. Sola, A. Nouri, J. Adv. Manuf. Process. 1, 2019. https:// doi.org/10.1002/amp2.10021

24. J. Metelkova, Y. Kinds, C. de Formanoir, A. Witvrouw, B. Van Hooreweder, in 30th Solid Freeform Fabrication Symposium, 2019

25. W.E. King, H.D. Barth, V.M. Castillo, G.F. Gallegos, J.W Gibbs, D. E. Hahn, C. Kamath, A.M. Rubenchik, J. Mater. Process. Technol. 214 (2014) 2915-2925

Cite this article as: Gheorghe Matache, Mihai Vladut, Alexandru Paraschiv, Raluca Mihaela Condruz, Edge and corner effects in selective laser melting of IN 625 alloy, Manufacturing Rev. 7, 8 (2020) 